\title{
AVALIAÇÃO SENSORIAL DE GOIABAS PASSAS OBTIDA POR TÉCNICAS COMBINADAS DE DESIDRATAÇÃO OSMÓTICA E SECAGEM
}

\author{
T. Pessoa, D. S. Amaral, M. E. M. Duarte, M. E. R. M. Cavalcanti Mata, F. F. Gurjão \\ Universidade Federal de Campina Grande - UFCG, Campina Grande - PB \\ pessoat@hotmail.com - denise.ufcg@gmail.com - elita@deag.ufcg.br -mmata@deag.ufcg.edu.br - \\ flavioggurjao@hotmail.com
}

Artigo submetido em julho/2011 e aceito em setembro/2011

\section{RESUMO}

A goiaba (Psiduim guajava L.) é utilizada não apenas para o consumo "in natura" como também para atender a uma demanda substancial para conservas industriais possibilitando, pela sua desidratação, um novo insumo nas indústrias alimentícias. Com vistas a atender a este mercado, o objetivo deste trabalho foi realizar a análise sensorial da goiaba passa da variedade Paluma obtida utilizando-se técnicas combinadas de desidratação osmótica e secagem convencional. Utilizaram-se goiabas nos estádios de maturação verde e madura, pré tratadas em solução de sacarose, com duas concentrações (40 e $50^{\circ}$ Brix) e submetidas à secagem em estufa com circulação de ar, em quatro temperaturas $\left(40,50,60\right.$ e $\left.70^{\circ} \mathrm{C}\right)$. A análise sensorial foi realizada através de teste de aceitação utilizando-se a escala hedônica de 5 pontos, avaliando os atributos aparência, cor, aroma e sabor. As goiabas passas no estádio de maturação verde foram as de melhor aceitabilidade; As passas obtidas pela secagem de 40 ㅇ $\mathrm{C}$ foi a de melhor aceitação sensorial.

PALAVRAS-CHAVE: Psidium guajava L; maturação; aceitação.

\section{SENSORY EVALUATION OF DRIED GUAVAS OBTAINED BY COMBINED TECHNIQUES OF DRYING AND OSMOTIC DEHYDRATION}

\section{ABSTRACT}

Guava (Psiduim guajava L.) is used not only for consumption "in natura" as well as to meet a substantial demand for industrial canning possible by its dehydration, a new ingredient in food. In order to serve this market, the objective is to guavas is sensorial Paluma variety obtained by using combined osmotic dehydration and conventional drying techniques. Guavas in mature and green stages of maturity were used in this. They were pretreated in sucrose concentrations ( 40 and $50^{\circ}$ Brix) and dried in stove with air circulation, at four temperatures $\left(40,50,60\right.$ and $70^{\circ}$ C). Sensory analysis was performed by test with 5 -point hedonic scale, assessing the attributes of appearance, color, aroma and flavor. Dried guavas in green maturity stage were the better acceptance; The raisins dried at 40 o $C$ obtaned the best sensorial acceptance.

KEY-WORDS: Psiduim guajava L; maturation; acceptance 


\section{AVALIAÇÃO SENSORIAL DE GOIABAS PASSAS OBTIDA POR TÉCNICAS COMBINADAS DE DESIDRATAÇÃO OSMÓTICA E SECAGEM}

\section{INTRODUÇÃO}

A goiaba (Psiduim guajava L.) é importante tanto para o consumo "in natura" como para atender a uma substancial demanda para conservas industriais, por possuir bom conteúdo de vitaminas $A$ e do complexo $B$, e também pelo alto teor de vitamina $C$ (ácido ascórbico), que supera àquele presente nos sucos cítricos (POMMER \& MURAKAMI, 2006). O seu processamento e a utilização da desidratação podem contribuir para o crescimento industrial, ensejando novos insumos nas indústrias alimentícias.

A exigência dos consumidores tem aumentado e produtos que preservam ao máximo suas características originais estão sendo preferidos. Em nível industrial, isto significa o desenvolvimento de operações que minimizam os efeitos adversos do processamento. Com isso a secagem vem prolongar a vida útil desses alimentos nas prateleiras de supermercados e restaurantes, e para que possa minimizar o efeito das temperaturas nesses alimentos, é necessário realizar estudos sobre as curvas de secagem e atividade de água na qual influenciam a qualidade do produto desidratado (PONTES et al., 2007).

O processo de secagem, pelo fato de envolver temperaturas consideravelmente altas para as frutas, por um longo período, causa alterações na composição dos alimentos, perda de nutrientes e modificações bastante significativas na sua estrutura e cor. Muitos autores têm sugerido a utilização da desidratação osmótica como pré tratamento para a secagem, por se mostrar como processo eficiente para a melhora da qualidade do produto final, por diminuir a perda de nutrientes voláteis e sensíveis a altas temperaturas durante a secagem, resultando também na obtenção de uma textura mais próxima do produto fresco. (CHIRALT et. al., 2001; FIOREZE, 2004; MASTRANTONIO et. al., 2006).

A desidratação osmótica, juntamente com a secagem convectiva, é um processo que permite a obtenção de frutas com melhor estabilidade de cor e textura e aumento da vida de prateleira, em relação ao produto convencionalmente seco e armazenado em temperatura ambiente (CÓRDOVA, 2006).

As combinações das técnicas de secagem dão origem a um novo produto, com características do produto "in natura", conservado e melhorado a partir da absorção dos solutos e da perda de água, possibilitando um nicho maior de mercado, o qual amplia o período de comercialização do produto, facilitando o armazenamento e o transporte, garantindo a qualidade necessária ao seu uso como insumo na indústria de alimentos.

O desenvolvimento de novos produtos acentua a necessidade de testes seguros, eficientes e representativos da opinião do consumidor, tanto quanto o estudo contínuo das mudanças nos hábitos alimentares. Os testes de preferência e aceitação com equipes de 
consumidores são indicados para avaliar, em termos de qualidade hedônica e aceitação, novos produtos lançados no comércio (TREPTOW et al., 1998).

A qualidade sensorial desses novos produtos esta ligada às percepções de cor, sabor, aroma, textura e aparência, sendo que o último atributo é o que mais influencia o consumidor na compra. Assim objetiva-se avaliar a qualidade sensorial de goiabas passa, obtidas de frutos em estádio de maturação verde e madura, elaboradas por técnicas combinadas de desidratação osmótica e secagem.

\section{MATERIAIS E MÉTODOS}

O trabalho foi conduzido no Laboratório de Armazenamento e Processamento de Produtos Agrícolas na Unidade Acadêmica de Engenharia Agrícola da Universidade Federal de Campina Grande-PB. Utilizaram-se goiabas da variedade Paluma em estádios de maturação verde e maduro, obtidas na Empresa de Abastecimentos e Serviços Agrícolas da Paraíba (EMPASA) e se utilizaram em média 60 quilos de goiaba. Os frutos foram lavados em água corrente; em seguida, sanificados em uma solução de 50 ppm de cloro livre, durante cinco minutos, e enxaguados em água destilada; logo após as goiabas foram colocadas para secar em bancadas sobre papel toalha.

Realizaram-se o descascamento e o corte dos frutos ao meio, no sentido longitudinal, procedendo-se a eliminação das sementes. Os frutos foram selecionados conforme integridade física e grau de maturação (verde e maduro) e a maturação foi classificada de acordo com a cor da polpa. As fatias de goiaba foram imersas em solução de sacarose em duas concentrações de 40 e $50{ }^{\circ}$ Brix na temperatura aproximada de $24{ }^{\circ} \mathrm{C}$ obtida pelo condicionamento de ar refrigerado por um período de 40 horas de osmose. As soluções osmóticas foram preparadas utilizando-se açúcar cristalizado adquirido em mercado local, na proporção produto: solução de 1:4. Após a desidratação osmótica as fatias de goiaba foram colocadas em estufa com circulação de ar, nas temperaturas de 40, 50, 60 e 70 C.

Testes de aceitação foram realizados para os parâmetros sabor, aroma, aparência, e cor, segundo MINIM (2006), para um grupo amostral de 40 provadores não treinados para cada tratamento; os testes foram conduzidos na Escola Municipal de Ensino Fundamental Médio Padre Simão Fileto, com provadores de ambos os sexos e idade entre 15 e 35 anos, de diferentes camadas sociais e dentro do grupo amostral (alunos, professores e funcionários).

Para realização da análise os provadores receberam as informações necessárias para esclarecimento da proposta do trabalho e como deveriam realizar a avaliação do teste; assim os julgadores analisaram as amostras segundo uma escala hedônica de 1 a 5 , a qual varia de desgostei muito a gostei muito, como consta a Figura 1. 
Para execução do teste as amostras foram cortadas em fatias de $3 \mathrm{~cm}^{2}$, as quais foram depositadas em copos descartáveis codificados com três números aleatórios. Para cada grupo de provadores foram analisadas quatro amostras de goiabas-passa por vez e juntamente com as mostras, foi servido biscoito água e sal, além de um copo com água mineral, para ser degustado entre cada prova, de forma a minimizar o sabor entre uma amostra e outra.

Para os parâmetros sensoriais realizou-se um teste fatorial $2 \times 2 \times 4$ correspondendo a dois níveis de maturação (verde e madura), dois tratamentos osmóticos (40 e $50{ }^{\circ} \mathrm{Brix}$ ) e quatro temperaturas de secagem $\left(40,50,60\right.$ e $\left.70{ }^{\circ} \mathrm{C}\right)$, utilizando-se o programa estatístico Assistat 7.5 beta. Para realizar a comparação entre as médias empregou-se a ANOVA e para calcular o grau de concordância entre os consumidores com relação às notas atribuídas, utilizou-se o Consensor (SILVA et al., 2008).

Figura 1- Modelo do formulário utilizado para análise dos atributos sensoriais TESTE DE ACEITAÇÃo

Amostra:

Data:

Nome:

sexo: $M(\quad) \quad F(\quad)$

Idade:

Por favor, avalie a amostra servida utilizando a escala abaixo e indique o quanto você gostou do produto

SABOR

( ) 5-Gostei muito

( ) 4-Gostei

( ) 3- Não gostei/ Nem desgostei.

( ) 2-Desgostei

( ) 1- Desgostei muito

\section{APARÊNCIA}

( ) 5-Gostei muito

( ) 4-Gostei

( ～～3- Não gostei/ Nem desgostei.

( ) 2-Desgostei

( ) 1-Desgostei muito
AROMA

( ) 5-Gostei muito

( ) 4-Gostei

( ～～3- Não gostei/ Nem desgostei.

( ) 2-Desgostei

( ) 1- Desgostei muito

COR

( ) 5-Gostei muito

( ) 4-Gostei

( ) 3- Não gostei/ Nem desgostei.

( ) 2-Desgostei

( ) 1- Desgostei muito 


\section{RESULTADOS E DISCUSSÃO}

Na Tabela 1 estão os resultados da análise de variância para análise sensorial da goiabapassa, quanto aos parâmetros de avaliação sabor, aroma, aparência e cor.

Tabela 1- Resumo da Análise de Variância (ANOVA) para os parâmetros: Sabor, Aroma, Aparência, Cor

\begin{tabular}{c|c|c|c|c|c}
\hline \multirow{2}{*}{ F.V } & \multirow{2}{*}{ G.L } & \multicolumn{4}{|c}{ Quadro Médio } \\
\cline { 3 - 6 } & & Sabor & Aroma & Aparência & Cor \\
\hline Maturação(M) & 1 & $0,90^{\mathrm{ns}}$ & $12,10^{* *}$ & $4,22^{\mathrm{ns}}$ & $19,25^{* *}$ \\
\hline Brix (B) & 1 & $0,16^{\mathrm{ns}}$ & $0,22^{\mathrm{ns}}$ & $0,76^{\mathrm{ns}}$ & $0,98^{\mathrm{ns}}$ \\
\hline Secagem (S) & 3 & $15,24^{* *}$ & $20,69^{* *}$ & $11,68^{* *}$ & $12,08^{* *}$ \\
\hline M x B & 1 & $2,76^{\mathrm{ns}}$ & $5,26^{*}$ & $8,56^{* *}$ & $4,39^{\mathrm{ns}}$ \\
\hline M x S & 3 & $0,90^{\mathrm{ns}}$ & $1,83^{\mathrm{ns}}$ & $1,79^{\mathrm{ns}}$ & $3,47^{*}$ \\
\hline B x S & 3 & $1,42^{\mathrm{ns}}$ & $2,61^{\mathrm{ns}}$ & $1,085^{\mathrm{ns}}$ & $0,69^{\mathrm{ns}}$ \\
\hline M x B x S & 3 & $0,87^{\mathrm{ns}}$ & $0,60^{\mathrm{ns}}$ & $0,77^{\mathrm{ns}}$ & $0,10^{\mathrm{ns}}$ \\
\hline Tratamentos & 15 & $3,74^{* *}$ & $6,32^{* *}$ & $3,97^{* *}$ & $4,91^{* *}$ \\
\hline Resíduo & 629 & 1,32 & 1,043 & 1,14 & 1,76 \\
\hline C.V (\%) & & 35,01 & 29,31 & 32,68 & 32,81 \\
\hline
\end{tabular}

** significativo ao nível de $1 \%$ de probabilidade pelo teste $\mathrm{F}$

* significativo ao nível de $5 \%$ de probabilidade pelo teste $\mathrm{F}$

ns não significativo

Verifica-se na Tabela 1 quanto ao parâmetro sabor, diferença significativa para o tratamento secagem e na interação maturação $X$ brix $X$ secagem; para o aroma observou-se diferença significativa para maturação e secagens e, para interações entre os tratamentos, ocorreram diferenças para a interação maturação $X$ brix.

Para o fator aparência foram significativas a secagem e a interação dos tratamentos maturação $X$ brix; com referência à cor, foram significativos a maturação e secagem e a interação dos tratamentos maturação $X$ secagem.

De modo geral, percebe-se significância para todos os tratamentos em todos os parâmetros de análise sensorial da goiaba-passa.

Na Tabela 2 se observam as médias dos tratamentos maturação, brix e secagem para as avaliações sensoriais da goiaba-passa, quanto aos parâmetros sabor, aroma, aparência e cor. 
Tabela 2- Médias dos fatores Brix e temperatura de secagem para os parâmetros: Sabor, Aroma, Aparência e Cor

\begin{tabular}{c|c|c|c|c}
\hline \multirow{2}{*}{ Fatores } & \multicolumn{4}{c}{ Médias } \\
\cline { 2 - 5 } & Sabor & Aroma & Aparência & Cor \\
\hline \multicolumn{5}{|c}{ Maturação } \\
\hline Verde & $3,25 \mathrm{a}$ & $3,62 \mathrm{a}$ & $3,35 \mathrm{a}$ & $3,47 \mathrm{a}$ \\
\hline Maduro & $3,32 \mathrm{a}$ & $3,35 \mathrm{~b}$ & $3,18 \mathrm{a}$ & $3,13 \mathrm{~b}$ \\
\hline \multicolumn{5}{|c}{ Brix } \\
\hline $\mathbf{4 0}$ & $3,27 \mathrm{a}$ & $3,46 \mathrm{a}$ & $3,23 \mathrm{a}$ & $3,26 \mathrm{a}$ \\
\hline $\mathbf{5 0}$ & $3,30 \mathrm{a}$ & $3,50 \mathrm{a}$ & $3,30 \mathrm{a}$ & $3,34 \mathrm{a}$ \\
\hline $\mathbf{4 0}$ & $3,67 \mathrm{a}$ & $3,88 \mathrm{a}$ & $3,66 \mathrm{a}$ & $3,69 \mathrm{a}$ \\
\hline $\mathbf{5 0}$ & $3,31 \mathrm{~b}$ & $3,59 \mathrm{ab}$ & $3,21 \mathrm{~b}$ & $3,30 \mathrm{~b}$ \\
\hline $\mathbf{6 0}$ & $3,21 \mathrm{bc}$ & $3,44 \mathrm{~b}$ & $3,13 \mathrm{~b}$ & $3,08 \mathrm{~b}$ \\
\hline $\mathbf{7 0}$ & $2,96 \mathrm{c}$ & $3,01 \mathrm{c}$ & $3,06 \mathrm{~b}$ & $3,13 \mathrm{~b}$ \\
\hline
\end{tabular}

Médias seguidas das mesmas letras na coluna não diferem entre si pelo teste de Tukey a $5 \%$ de probabilidade

Para a avaliação sensorial utilizou-se uma escala de 1 a 5 , em que quanto mais próximo de 5 ocorria uma aceitabilidade melhor do produto. Percebe-se pela Tabela 2 que, para o tratamento maturação, ocorreu maior aceitabilidade de sabor para as amostras maduras analisando os atributos aroma, aparência e cor, percebe-se que as goiabas-passa elaboradas com goiabas verdes obtiveram melhor aceitação e, quanto ao teor de sólidos solúveis (Brix) não ocorreram diferenças significativas entre os tratamentos.

Quando se avaliaram as temperaturas de secagem observou-se que as goiabas-passa obtidas através da secagem a $40{ }^{\circ} \mathrm{C}$ foram as de maior aceitabilidade para todos os parâmetros sensoriais. Esse fato pode ser justificado, porque as goiabas secas nas temperaturas mais baixas apresentaram uma menor rigidez, facilitando o processo de mastigação. Assim o aspecto da textura, foi decisório na aceitação do produto.

Na Tabela 3 encontra-se a análise do desdobramento da interação significativa entre os tratamentos maturação e brix, para o parâmetro aroma. 
Tabela 3- Desdobramento da interação significativa entre maturação e ${ }^{\circ}$ brix para o parâmetro aroma

\begin{tabular}{c|c|c}
\hline \multirow{2}{*}{ Maturação } & \multicolumn{2}{|c}{ AROMA } \\
\cline { 2 - 3 } & \multicolumn{2}{|c}{${ }^{\circ}$ Brix } \\
\cline { 2 - 3 } & $\mathbf{4 0}$ & $\mathbf{5 0}$ \\
\hline Verde & $3,51 \mathrm{aA}$ & $3,73 \mathrm{aA}$ \\
\hline Maduro & $3,41 \mathrm{aA}$ & $3,27 \mathrm{bA}$ \\
\hline
\end{tabular}

Médias seguidas das mesmas letras (maiúscula nas linhas e minúscula nas colunas) não diferem entre si pelo teste Tukey a 5\% de probabilidade

Pode-se observar no desdobramento da interação Maturação X Brix, que a maior média, de 3,73 foi obtida para goiaba passa obtida de frutos de maturação verde desidratadas em solução de sacarose a $50^{\circ}$ brix.

$\mathrm{Na}$ Tabela 4 se encontra a análise do desdobramento da interação significativa entre maturação e ${ }^{\circ}$ Brix, para o parâmetro aparência.

Tabela 4- Desdobramento da interação significativa entre maturação e ${ }^{\circ}$ Brix, para o parâmetro aparência

\begin{tabular}{c|c|c}
\hline \multirow{2}{*}{ Maturação } & \multicolumn{2}{|c}{ APARÊNCIA } \\
\cline { 2 - 3 } & \multicolumn{2}{|c}{${ }^{\circ}$ Brix } \\
\cline { 2 - 3 } & $\mathbf{4 0}$ & $\mathbf{5 0}$ \\
\hline Verde & $3,20 \mathrm{aA}$ & $3,50 \mathrm{aA}$ \\
\hline Maduro & $3,26 \mathrm{aA}$ & $3,10 \mathrm{bA}$ \\
\hline
\end{tabular}

Médias seguidas das mesmas letras (maiúscula nas linhas e minúscula nas colunas) não diferem entre si pelo teste Tukey a 5\% de probabilidade

Observando a Tabela 4, percebe-se que o tratamento verde desidratado a $50{ }^{\circ} \mathrm{Brix}$ foi o tratamento que obteve a maior média 3,50.

Na Tabela 5 se encontra a análise do desdobramento da interação significativa entre ${ }^{\circ}$ Brix e temperatura de secagem, para o parâmetro cor. 
Tabela 5- Desdobramento da interação significativa entre ${ }^{\circ}$ brix e temperatura de secagem, para o parâmetro cor.

\begin{tabular}{c|c|c|c|c}
\hline \multirow{2}{*}{${ }^{\circ}$ Brix } & \multicolumn{4}{|c}{ COR } \\
\cline { 2 - 5 } & \multicolumn{4}{|c}{ Temperatura ( $\left.{ }^{\circ} \mathbf{C}\right)$} \\
\cline { 2 - 5 } & $\mathbf{4 0}$ & $\mathbf{5 0}$ & $\mathbf{6 0}$ & $\mathbf{7 0}$ \\
\hline $\mathbf{4 0}$ & $3,78 \mathrm{aA}$ & $3,68 \mathrm{aAB}$ & $3,15 \mathrm{aC}$ & $3,28 \mathrm{aBC}$ \\
\hline $\mathbf{5 0}$ & $3,60 \mathrm{aA}$ & $2,91 \mathrm{bB}$ & $3,02 \mathrm{aB}$ & $2,98 \mathrm{aB}$ \\
\hline
\end{tabular}

Médias seguidas das mesmas letras (maiúscula nas linhas e minúscula nas colunas) não diferem entre si pelo teste Tukey a 5\% de probabilidade

Percebe-se pela Tabela 5, que o tratamento $40^{\circ}$ Brix com secagem de $40^{\circ} \mathrm{C}$, foi melhor avaliado.

$\mathrm{Na}$ Tabela 6 tem-se as médias e coeficiente de concordância entre julgadores (CC) da análise sensorial da goiaba-passa nos estádios de maturação verde e madura, desidratada osmoticamente e secas em estufa com circulação de ar, quanto aos parâmetros sabor, aroma, aparência e cor. 
Tabela 6- Médias e coeficiente de concordância entre julgadores (CC) da análise sensorial de goiaba-passa desidratada osmoticamente e secas em estufa com circulação de ar, quanto aos parâmetros sabor, aroma, aparência e cor.

\begin{tabular}{|c|c|c|c|c|c|c|c|c|c|c|}
\hline Maturação & $\begin{array}{c}\text { Desidratação } \\
\text { Osmótica }\end{array}$ & $\begin{array}{c}\text { Temperatura } \\
\text { de Secagem }\end{array}$ & \multicolumn{2}{|c|}{ Sabor } & \multicolumn{2}{|c|}{ Aroma } & \multicolumn{2}{|c|}{ Aparência } & \multicolumn{2}{|c|}{ Cor } \\
\hline \multirow{9}{*}{ Verde } & \multirow{5}{*}{40} & & Média & CC \% & Média & CC \% & Média & CC \% & Média & CC \% \\
\hline & & 40 & 3,73 & 47,93 & 3,95 & 51.39 & 3,63 & 42,84 & 3,7 & 42,57 \\
\hline & & 50 & 3,48 & 25,92 & 3,78 & 38.93 & 3,2 & 14,25 & 3,05 & 24,22 \\
\hline & & 60 & 3,35 & 17,23 & 3,15 & 21.64 & 3,18 & 21,28 & 3,00 & 33,07 \\
\hline & & 70 & 2,95 & 16,68 & 2,80 & 15.81 & 3,08 & 20,54 & 2,95 & 21,28 \\
\hline & \multirow{4}{*}{50} & 40 & 3,78 & 54,91 & 3,63 & 44.55 & 3,55 & 54,77 & 3,50 & 41,83 \\
\hline & & 50 & 3,40 & 25,22 & 3,38 & 29.84 & 3,03 & 22,39 & 2,78 & 33,46 \\
\hline & & 60 & 3,00 & 21,7 & 3,40 & 36.65 & 3,2 & 31,11 & 3,05 & 23,04 \\
\hline & & 70 & 2,93 & 17,11 & 2,70 & 19.76 & 2,65 & 26,1 & 3,03 & 10,46 \\
\hline \multirow{8}{*}{ Maduro } & \multirow{4}{*}{40} & 40 & 3,45 & 38,93 & 4,05 & 47,6 & 3,53 & 49,21 & 3,68 & 30,87 \\
\hline & & 50 & 3,3 & 23,39 & 3,53 & 30,62 & 3,35 & 38,13 & 3,63 & 36,01 \\
\hline & & 60 & 3,18 & 24,92 & 3,43 & 42,2 & 2,85 & 27,95 & 2,98 & 23,04 \\
\hline & & 70 & 2,75 & 18,76 & 3,05 & 20,92 & 3,08 & 35,36 & 3,15 & 28,23 \\
\hline & & 40 & 3,75 & 47,27 & 3,90 & 56.32 & 3,95 & 43,48 & 3,90 & 49,21 \\
\hline & & 50 & 308 & 33,77 & 3,70 & 40.89 & 3,30 & 31,12 & 3,75 & 51,08 \\
\hline & & 60 & 3,30 & 19,54 & 3,80 & 46.94 & 3,30 & 25,22 & 3,33 & 40,12 \\
\hline & & 70 & 3,20 & 22,01 & 3,53 & 30.87 & 3,45 & 35,14 & 3,43 & 3,36 \\
\hline
\end{tabular}

CC: coeficiente de concordância entre os julgadores

Na Tabela 4.18 se verificam as concordâncias com as médias das notas dos julgadores para análise sensorial das goiabas-passa; pode-se observar, para o parâmetro sabor, que o tratamento com maior concordância foi para passa de goiaba verde desidratada osmoticamente a $50{ }^{\circ} \mathrm{Brix}$ e seca a $40{ }^{\circ} \mathrm{C}$, com média de notas de 3,78 e coeficiente de concordância de $54,91 \%$.

Para o parâmetro sensorial aroma, a maior média de notas foi para a goiaba-passa madura, submetida à desidratação osmótica a $40^{\circ}$ Brix e seca a $40^{\circ} \mathrm{C}$, a qual obteve média de 4,05; essa média merece destaque por se aproximar de 5 dentro na escala hedônica das notas; com relação ao coeficiente de concordância, o tratamento com maior percentual foi para a goiaba madura desidratada em solução de $50^{\circ} \mathrm{Brix}$ e seca à temperatura de $40^{\circ} \mathrm{C}$, com um CC de 56,32\% para a média de 3,90. 
Para o parâmetro sensorial aparência, observou-se a maior média para a goiaba-passa madura tratada com $50{ }^{\circ}$ Brix de desidratação osmótica e seca a $40{ }^{\circ} \mathrm{C}$, cuja média foi 3,95. Quando se avalia o melhor CC, percebe-se que a goiaba-passa verde tratada em solução osmótica de $50{ }^{\circ}$ Brix e seca a $40{ }^{\circ} \mathrm{C}$ apresentou o maior valor de $54,77 \%$, para a média de 3,5.

Quando se avaliou o parâmetro sensorial cor, a maior média 3,90, foi obtida para goiaba passa obtida a partir do fruto maduro desidratada osmoticamente a $50^{\circ} \mathrm{Brix}$ e seca a $40^{\circ} \mathrm{C}$; já o maior índice de concordância ( CC) foi de $51,08 \%$ concedido para a média de 3,75 , nota essa concedida para goiaba-passa obtida de frutos maduros e tratados em solução de sacarose a $50^{\circ}$ Brix e secas a $50^{\circ} \mathrm{C}$.

\section{CONCLUSÃO}

A maior aceitação foi para as goiabas passas elaboradas com frutos no estádio de maturação verde;

Passas secas a $40^{\circ} \mathrm{C}$ obtiveram a melhor avalição sensorial;

A secagem a $40{ }^{\circ} \mathrm{C}$ para a obtenção das goiabas passa nos estádios de maturação verde e madura e as desidratações osmóticas em solução de sacarose a 40 e $50{ }^{\circ} \mathrm{Brix}$, obtiveram os melhores coeficientes de concordância dos provadores.

\section{REFERÊNCIAS BIBLIOGRAFICAS}

1. ChIRALT, A.; MARTínEZ-NAVARRETE, N.; MARTíNEZ-MONZÓ, J.; TALENS, P.; MORAGA, G.; AYALA, A.; FITO, P. Changes in mechanical properties throughout osmotic process: Cryprotectant effect. Journal of Food Engineering, v. 49, p.129-135, 2001.

2. CÓRDOVA, K. R. V. Desidratação osmótica e secagem convectiva de maçã Fuji comercial e industrial. 148f, 2006. Dissertação. (Mestrado em Tecnologia de Alimentos). Setor de Tecnologia da Universidade Federal do Paraná.

3. FIOREZE, R. - Princípios de secagem de produtos biológicos - João Pessoa: Editora Universitária/UFPB, 2004. 229 p.

4. MASTRANTONIO, S. D. S.; PEREIRA, L. M.; HUBINGER, M. D. Mass transfer and difusion coeficient determination in osmotically dehydrated guavas. 15th International Drying Symposium (IDS 2006), Budapest, Hungary, 20-23 August, p.860-870, 2006. 
5. POMMER, C. V.; MURAKAMI, K. R. N. A goiaba no mundo. O agrônomico, Campinas, p. 22-26, fev. 2006.

6. PONTES, S. F. O.; BONOMO, R. C. F.; PONTES, L. V.; RIBEIRO, A. C.; CARNEIRO, J. C. S. Secagem e Avaliação Sensorial de Banana da Terra. Revista Brasileira de Produtos Agroindustriais. v.9, n.2, p.143-148, 2007.

7. SILVA, F. A. S.; DUARTE, M. E. M.; CAVALCANTI MATA, M. E. R. M. Nova metodologia para interpretação de dados de análise sensorial de alimentos. Revista Engenharia Agrícola. V. 30, n.5, p.967-973, set./out. 2010.

8. TREPTOW, R. O.; QUEIROZ, M. I., ANTUNES, P. L. Preferência e Aceitação de Fatias Desidratadas de Maçãs (Malus domestica Borkh). Revista Brasileira de Agrociência. V. 4, n. 1, p. 41-46, 1998. 